\title{
Linkage of blood pressure, obesity and diabetes mellitus with angiotensinogen gene (AGT 704T $>$ C/rs699) polymorphism in hypertensive patients
}

\author{
Repchuk $\mathrm{Y}^{1}$, Sydorchuk LP${ }^{1}$, Sydorchuk AR ${ }^{2}$, Fedonyuk LY ${ }^{4}$, Kamyshnyi $\mathrm{O}^{3}$, Korovenkova $\mathrm{O}^{1}$, \\ Plehutsa $\mathrm{IM}^{6}$, Dzhuryak VS ${ }^{1}$, Myshkovskii $\mathrm{YM}^{6}$, Iftoda $\mathrm{OM}^{5}$, Sydorchuk $\mathrm{RI}^{6}$
}

Bukovinian State Medical University, Family Medicine Department, Chernivtsi, Ukraine. Isydorchuk@bsmu.edu.ua

\begin{abstract}
AIMS: The study aim was to analyse the frequency of polymorphic variants of angiotensinogen gene polymorphism (AGT 704T>C, rs699) in essential arterial hypertension (EAH) patients.

METHODS: Seventy-two individuals with EAH and hypertension-mediated organ damage (stage 2), moderate, high or very high cardiovascular risks were involved in the case-control study. Among them, $70.84 \%$ (51) were females and $29.16 \%$ (21) were males; mean age was $59.87 \pm 7.98 \mathrm{y}$. The control group consisted of fifty practically healthy individuals at relevant age $(49.13 \pm 6.28 \mathrm{y}$ ) and with relevant sex distribution (62\% were females, $38 \%$ were males). AGT $(704 \mathrm{~T}>\mathrm{C})$ gene polymorphism was examined by RT-PCR.

RESULTS: The distribution of genotypes in the study group was as follows: TT $-14 \%$, TC $-60 \%$, CC $26 \%$, which corresponded to the distribution in the control group - $16 \%, 54 \%$ and $30 \%$, respectively, and did not deviate from the Hardy-Weinberg equilibrium. Smoking, type 2 diabetes mellitus (DM2) and obesity increased the relative risk of EAH in the examined population 2.5 times [OR=2.81; $p=0.049$ ], 3.75 times [OR=4.68; $p=0.005$ ] and almost twofold [OR=2.90; $p=0.004$ ], respectively. The probability of EAH increases fourfold with the angiotensin II elevation in the serum. Genotypes and alleles of the AGT (704T>C) gene were not significant risk factors for EAH and DM2 in the studied population. However, the TC-genotype (lesser T-allele) increases the risk of obesity in EAH patients more than 1.5 times [OR=2.93; $p=0.03$ ]. In addition, the T-allele increases the risk for blood pressure (BP) to elevate up to grade $2-3$ [OR=3.64; $p<0.001$ ]. CONCLUSIONS: One-way ANOVA analysis confirmed the AGT $(704 \mathrm{~T}>\mathrm{C})$ gene polymorphism to be associated with systolic and diastolic BP elevation ( $F=7.80 ; p<0.001$ and $F=4.90 ; p=0.01$, respectively), especially in TT-genotype carriers $(p<0.05)$, and with body mass index increase, albeit only in women $(\mathrm{F}=13.94 ; \mathrm{p}<0.001)$ (Tab. 4, Fig. 3, Ref. 26). Text in PDF www.elis.sk KEY WORDS: angiotensinogen gene (AGT 704T>C), diabetes mellitus type 2, arterial hypertension, obesity, risk.
\end{abstract}

\section{Introduction}

Essential (primary) arterial hypertension (EAH) remains the most common non-infectious disease worldwide. The global prevalence of hypertension in adults is about $30-45 \%$ with a standardized prevalence of $24 \%$ and $20 \%$ in men and women, respectively. The EAH prevalence exceeds $60 \%$ after the age of sixty.

${ }^{1}$ Family Medicine Department, Bukovinian State Medical University, Chernivtsi, Ukraine, ${ }^{2}$ Emergency and Trauma Surgery Department, St. Anna Hospital, Herne, Germany, ${ }^{3}$ Department of Microbiology, Virology and Immunology, Ternopil National Medical University, Ternopil, Ukraine, ${ }^{4}$ Department of Biology, Ternopil National Medical University, Ternopil, Ukraine, ${ }^{5}$ Department of Hygiene and Ecology, Bukovinian State Medical University, Chernivtsi, Ukraine, and ${ }^{6}$ Department General Surgery, Bukovinian State Medical University, Chernivtsi, Ukraine

Address for correspondence: L. Sydorchuk, Prof, MD, PhD, Bukovinian State Medical University, Family Medicine Department, Theatre Sq., 2. 58004, Chernivtsi, Ukraine

Phone: +380678784456 , Fax: +380372553754
The numbers of hypertensive patients continue to grow, while it is predicted that as many as 1.5 billion individuals will be suffering from arterial hypertension in $2025(1,2)$.

Hypertension is a multifactorial disease with the interaction of many risk factors, and environmental and strong genetic backgrounds (3). The most studied genetic factors are those involved in the renin-angiotensin-aldosterone system activity (RAAS), such as angiotensinogen gene (AGT), angiotensin-converting enzyme (ACE), angiotensin II receptor gene (AGTRII), as well as modified factors such as obesity, increased body mass index (BMI), excessive salt intake, alcohol consumption, stress, low levels of high density lipids (HDL) and total cholesterol increase (4-9). Genes determine approximately $20-60 \%$ of blood pressure (BP) variability and some peculiarities of hypertension-mediated organ damage in different populations (10-15).

The AGT gene is a highly polymorphic gene with more than 40 single nucleotide substitutions. It is located on chromosome 1 , in the locus $1 \mathrm{q} 42-\mathrm{q} 43$, in the same region as the renin gene, and contains 5 exons. SNPs localized in the 2 nd exon were most 


\section{5-720}

often studied. Replacement of thymine (T) by cytosine (C) in the 704th position (T704C) leads to the inclusion of tryptophan in the protein instead of methionine (M268T, M235T), and the replacement of cytosine with thymine at position 521 (C521T) leads to the replacement of threonine with methionine (T207M, T174M). The protein encoded by this gene, pre-angiotensinogen (precursor of angiotensinogen), is expressed in the liver and is broken down by renin in response to low BP. The resulting product, angiotensin I, is then cleaved by ACE to form the physiologically active angiotensin II. Protein is involved in maintaining BP, fluid homeostasis and electrolytes in the body. AGT gene mutations lead to the increase in its expression and AGT blood level and are associated with hypertension and some other cardiovascular (CV) pathologies $(10-12,16)$.

Therefore, the study aim was to analyze the frequency of polymorphic variants of $A G T(704 T>C)$ gene polymorphism (Met235Thr, rs699) and find its possible association with blood pressure, diabetes mellitus and obesity in EAH patients.

\section{Materials and methods}

\section{Study population and compliance with bioethics}

After screening the matching inclusion and exclusion criteria, one-hundred patients were selected for further examination, while the genetic examination was performed in 72 cases. Among them, $70.84 \%(51)$ were females and $29.16 \%(21)$ were males, while the mean age was $59.87 \pm 7.98 \mathrm{y}$. The control group consisted of fifty practically healthy individuals at relevant age $(49.13 \pm$ 6.28 yo) and with relevant sex distribution (62\% were females, $38 \%$ were males). Age, sex, family history of CAD, body mass index, smoking status, and history of hypertension, hyperlipidemia, and DM2 were recorded for each study subject. All par- ticipants gave written informed consent, and the Institutional Ethics Committee approved the study protocol in compliance with the European Convention on Human Rights and Biomedicine, GCP, EUC directive \#609 and other EU and international legislations on bioethics.

\section{Inclusion/exclusion criteria}

Inclusion criteria. EAH patients were included in the current study with hypertension-mediated organ damage (target organ damage of severity stage 2, asymptomatic disease), from grade 1 through to grade 3 of BP values; moderately high CV risk; age over $30 \mathrm{y}$. All enrolled subjects signed a consent form before participating in the study.

Exclusion criteria. We excluded patients with EAH stage 3 (identified CV disease), chronic heart failure (CHF) higher than functional class II (NYHA III-IV), EAH patients with complications of hypertension-mediated organ damage, secondary AH, diabetes mellitus type I (DM 1), sub- and decompensated DM 2 (with diabetes target organ damage), malignant or uncontrolled $\mathrm{AH}$, sub- and decompensated diseases of the liver (three times over the norm level of aspartate aminotransferase, alanine aminotransferase), bronchial asthma, chronic obstructive pulmonary disease of stage III-IV with C or D risk value (GOLD, 2019), exacerbated infectious diseases or stage of unstable remission, psychological disorders, oncologic problem of any location, taking oral corticosteroids or contraceptives, and pregnancy or lactation period. More detailed information about inclusion and exclusion criteria is listed in our previous papers (17-19).

\section{Diagnosis of arterial hypertension}

Hypertension was defined as office SBP values $\geq 140 \mathrm{mmHg}$ and/or diastolic BP (DBP) values $\geq 90 \mathrm{mmHg}$ at least for three

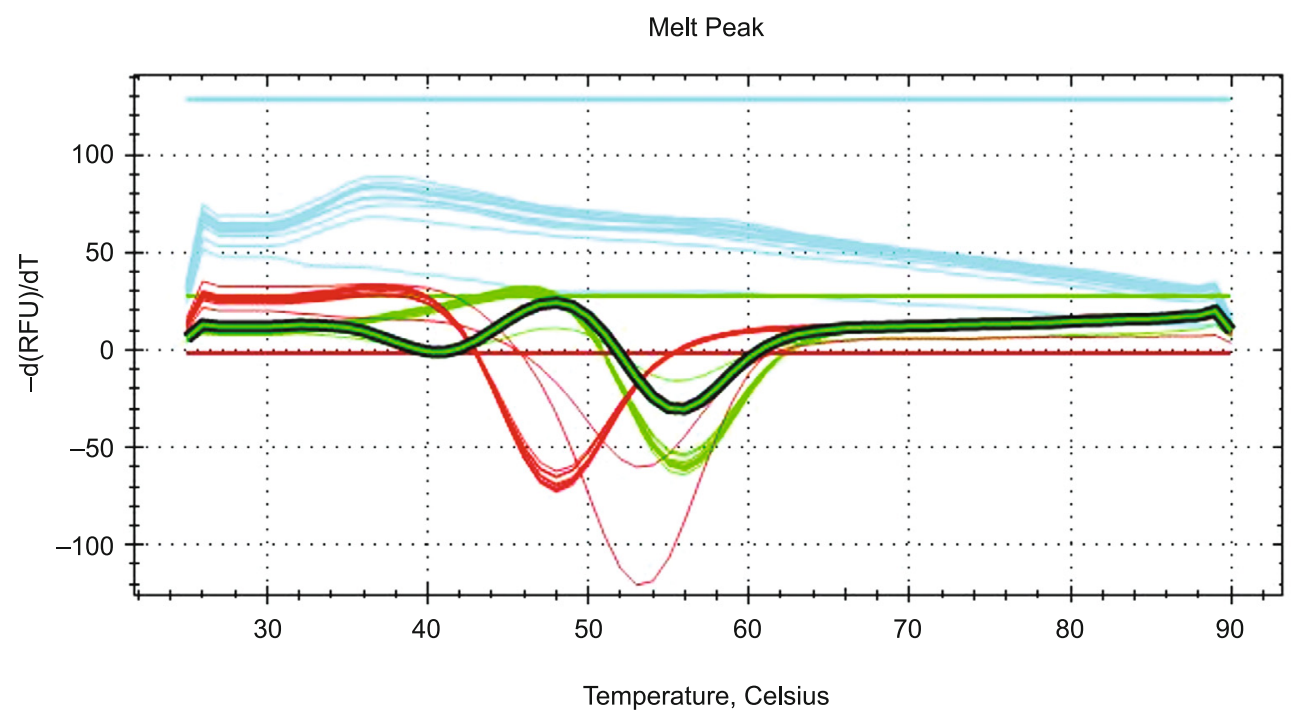

Fig. 1. Temperature bars in analysis of $A G T$ 704T $>C$ gene's polymorphism in observed population: blue color shows the samples homozygous for the $T$-allele of the $A G T$ gene $(704 T>C)$, determined by the Fam channel; green - samples homozygous for Hex channel ( $C$-allele); Reds heterozygous (TC) specimens; violet - questionable and unreliable results. 


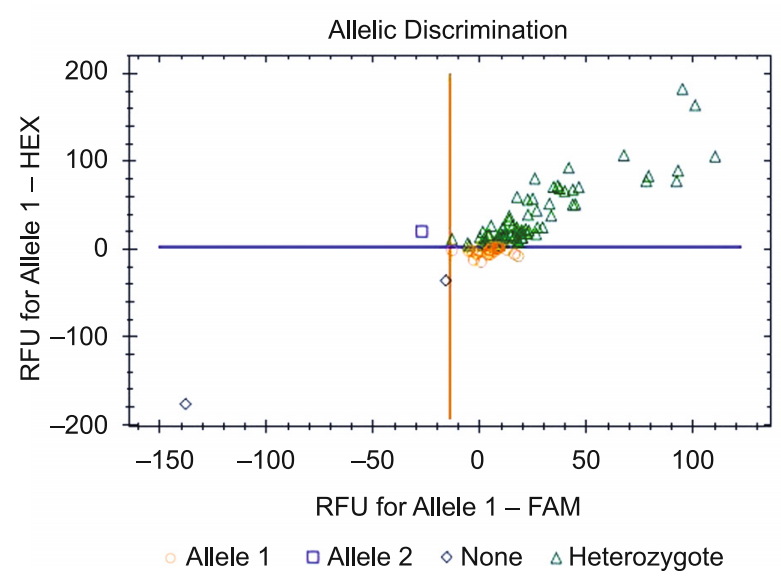

Fig. 2. Allelic discrimination of $A G T$ 704T $>C$ gene's polymorphism: oAllele 1 - TT-genotype carriers; Ž Allele 2 - CC-genotype carriers; DHeterozygote - TC-genotype carriers; àNone - not determined

measurements during one month, according to national and European Societies of Hypertension and Cardiology (ESH/ESC, 2016, 2018) recommendations requirement. Left ventricular hypertrophy was confirmed by electrocardiography (ECG) and/or echocardiography (EchoCG).

All enrolled patients underwent a complex of basic examinations: general clinical analyses of $\mathrm{CBC}$, total cholesterol level and low/high density level cholesterol (LDL-, HDL-C), BMI $\left(\mathrm{kg} / \mathrm{m}^{2}\right)$ for evaluation of overweight and abdominal obesity (AO), waist-to-hip ratio (WHR), office measurement of SBP, DBP, heart rate (HR), ECG in 12 leads, EchoCG, consultations of ophthalmologist and neurologist according to ESC/ESH 2018 European recommendations (2).
Genotyping of the angiotensinogen (AGT 704T>C) gene polymorphism

DNA extraction. Venous blood was collected into a sterile vacutainer, and stabilized by K2-EDTA. DNA was extracted from the whole venous blood lymphocytes' nuclei of participants. The isolation and purification of DNA from the obtained material was performed according to Thermo Scientific GeneJET Genomic DNA Purification Kit Manufacturer's Guidance (Thermo Fisher Scientific, Waltham, MA, USA).

DNA amplification and genotyping. Quantitative real-time PCR (qRT-PCR) was used for DNA fragments of AGT 704T $>C$ gene amplification and performed on CFX96 Touch ${ }^{\mathrm{TM}}$ (Bio-Rad Laboratories Inc, USA). Genotyping was performed with specific TaqMan catheters/probe by CFX96 RT-PCR Detection System. The amplification mixture compounded PCR buffer, Taq-AT polymerase and mineral oil. Further, the TaqMan signal probe containing fluorescent labels Fam (samples homozygous for $T$ allele of the AGT gene $(704 T>C)$ on the Fam channel) and Hex (samples homozygous for the $C$ allele of the AGT gene on the Hex channel) were added to the amplification mixture with the aim to detect duplexes formed by amplicons and signal probes during PCR melting. The melting point of the TaqMan signal probes was fixed by the software of the CFX96 Thermocycler according to the partial (lower temperature) or full (higher temperature) complementarity of the TaqMan probe to the target DNA of the amplicon, resulting in different levels of fluorescence and corresponding temperature graphs. The DNA fragments amplification (amplicons) analysis of AGT $(704 T>C)$ gene polymorphism was performed by the licensed CFX96 RT-PCR Detection System Software (Microsoft, Redmond, WA, USA). The obtained images are presented in Figures 1-3.

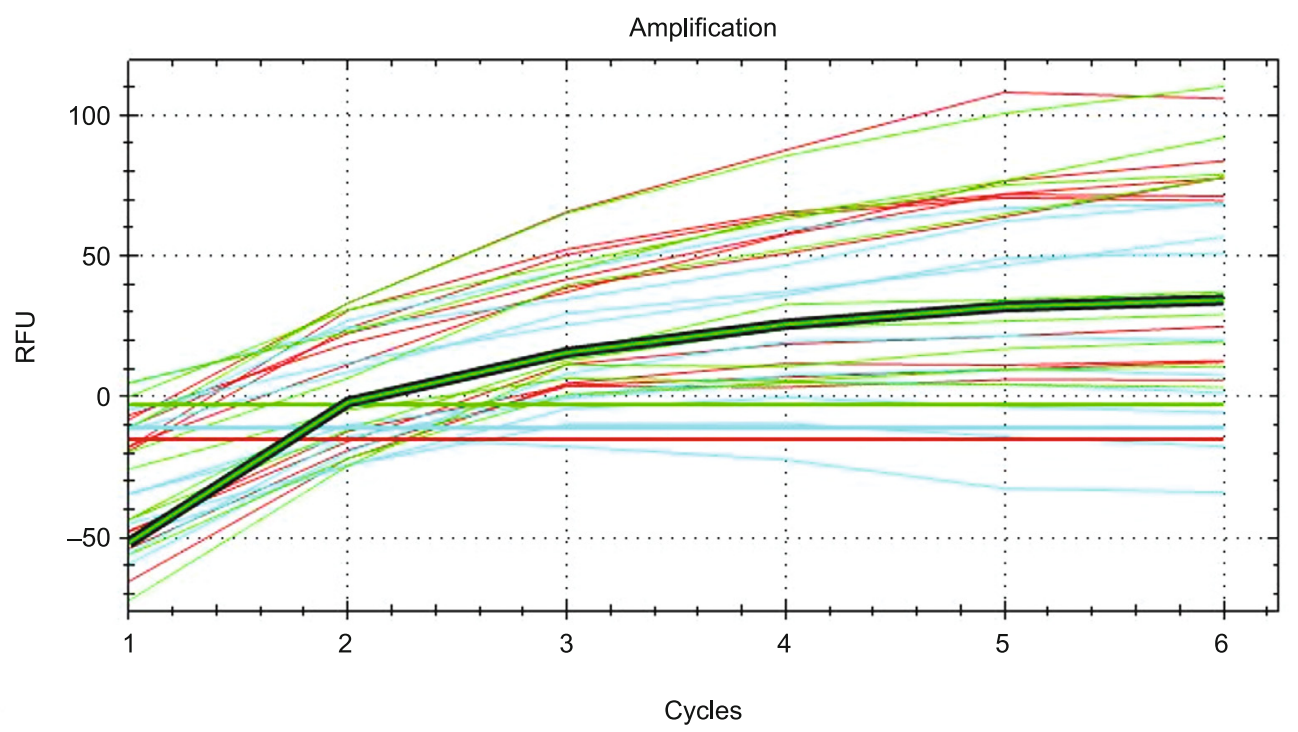

Figure 3. AGT 704T $>C$ gene's polymorphism amplification according to the full qRT-PCR protocol cycles: blue color shows the samples homozygous for the $T$-allele of the $A G T$ gene $(704 T>C)$, determined by the Fam channel; green - samples homozygous for Hex channel $(C$-allele); Red - heterozygous (TC) specimens. 
Tab. 1. Clinical and demographic indicators depending on polymorphic variants of the AGT gene.

\begin{tabular}{|c|c|c|c|c|c|c|c|}
\hline \multirow{2}{*}{ Parameters } & & \multicolumn{3}{|c|}{ AGT Genotypes in Control group, $\mathrm{n}=50$} & \multicolumn{3}{|c|}{ AGT gene genotypes in Study group, $n=72$} \\
\hline & & $\mathrm{TT}, \mathrm{n}=8$ & $\mathrm{TC}, \mathrm{n}=27$ & $\mathrm{CC}, \mathrm{n}=15$ & $\mathrm{TT}, \mathrm{n}=10$ & $\mathrm{TC}, \mathrm{n}=43$ & $\mathrm{CC}, \mathrm{n}=19$ \\
\hline \multirow{2}{*}{ Sex, n $(\%)$} & $\mathrm{F}$ & $4(50 \%)$ & $17(63 \%)$ & $10(67 \%)$ & $8(80 \%)$ & $30(70 \%)$ & $13(68 \%)$ \\
\hline & $\mathrm{M}$ & $4(50 \%)$ & $10(37 \%)$ & $5(33 \%)$ & $2(20 \%)$ & $13(30 \%)$ & $6(32 \%)$ \\
\hline \multicolumn{2}{|l|}{ Heredity, n (\%) } & $4(50 \%)$ & $20(74 \%)$ & $13(86.7 \%)$ & $8(80 \%)$ & $29(67 \%)$ & $15(79 \%)$ \\
\hline \multicolumn{2}{|l|}{$\mathrm{DM} 2, \mathrm{n}(\%)$} & 0 & 0 & 0 & $2(20 \%)$ & $11(26 \%)$ & $7(37 \%)$ \\
\hline \multicolumn{2}{|l|}{ Smoking, n (\%) } & 0 & $2(7.4 \%)$ & $2(13.3 \%)$ & $1(10 \%)$ & $10(23 \%)$ & $4(21 \%)$ \\
\hline \multirow{2}{*}{$\begin{array}{l}\mathrm{BMI}, \mathrm{kg} / \mathrm{m}^{2} \\
\mathrm{M} \pm \mathrm{m}\end{array}$} & M & $29.84 \pm 3.18$ & $26.10 \pm 1.78$ & $29.78 \pm 2.24$ & $30.06 \pm 2.94$ & $\begin{array}{l}31.9 \pm 4.59 \\
\mathrm{p}=0.012\end{array}$ & $30.13 \pm 3.18$ \\
\hline & $\mathrm{F}$ & $24.52 \pm 1.45$ & $26.55 \pm 3.81$ & $23.89 \pm 3.70$ & $28.25 \pm 3.32$ & $\begin{array}{l}33.65 \pm 4.15 \\
\mathrm{p}=0.01 \\
\mathrm{p}_{\mathrm{TT}}<0.05\end{array}$ & $\begin{array}{l}29.25 \pm 2.97 \\
\mathrm{p}_{\text {тс }}<0.05\end{array}$ \\
\hline \multirow{4}{*}{ BMI, n (\%) } & Normal & $2(25 \%)$ & $11(40.7 \%)$ & $7(46.6 \%)$ & $2(20 \%)$ & $1(2 \%)$ & $3(16 \%)$ \\
\hline & Overweight & $4(50 \%)$ & $12(44.5 \%)$ & $4(26.7 \%)$ & $2(20 \%)$ & $13(30 \%)$ & $8(42 \%)$ \\
\hline & Obesity $1^{\text {st }}$ st. & $2(25 \%)$ & $2(7.4 \%)$ & $4(26.7 \%)$ & $6(60 \%)$ & $12(28 \%)$ & $6(32 \%)$ \\
\hline & Obesity $2^{\text {nd }-} 3^{\text {rd }}$ st. & 0 & $2(7.4 \%)$ & 0 & 0 & $17(40 \%)$ & $2(11 \%)$ \\
\hline \multirow{4}{*}{$\begin{array}{l}\text { WHR, } \\
\text { n (\%) }\end{array}$} & Elevated & 0 & $4(23.5 \%)$ & $4(40 \%)$ & $7(88 \%)$ & $26(87 \%)$ & $9(69 \%)$ \\
\hline & Normal & $4(100 \%)$ & $13(76.5 \%)$ & $6(60 \%)$ & $1(12 \%)$ & $4(13 \%)$ & $4(31 \%)$ \\
\hline & Elevated & $4(100 \%)$ & $8(80 \%)$ & $5(100 \%)$ & $1(50 \%)$ & $13(100 \%)$ & $6(100 \%)$ \\
\hline & Normal & 0 & $2(20 \%)$ & 0 & $1(50 \%)$ & 0 & \\
\hline
\end{tabular}

$\mathrm{M}$ - males, F - females, BMI - body mass index, WHR - waist-to-Hip ratio, DM2 - diabetes mellitus type 2.

$\mathrm{p}$ : shows significance of differences with control group of the same genotype, $\mathrm{p}_{\mathrm{TT}}, \mathrm{p}_{\mathrm{Tc}}$ - significance of differences for TT-, TC-genotypes carriers in particular group (control/patients)

\section{Statistical analysis}

Statistical analysis was performed using Statistica 7.0 (StatSoft Inc., Tulsa, OK, USA) software. For the genotypes distribution comparison we used Pearson's criterion $(\chi 2)$. Analysis of qualitative data (categorical variables), risk of pathology development was assessed by a binary logistic regression model using relative risk (RelR); risk ratio (RR) was estimated by odds ratio (OR) with $95 \%$ confidence interval $[95 \% \mathrm{CI}]$ using a chi-square test $(\chi 2)$ $(\mathrm{df}=1)$; one-way ANOVA analysis was used to confirm the association of AGT (rs699) gene with clinical and diagnostic laboratory parameters. $\mathrm{P}$ values $<0.05$ were considered statistically significant.
Tab. 2. Potential risk factors of essential arterial hypertension in observed population.

\begin{tabular}{llccccc}
\hline \multirow{2}{*}{ Potential risk factor } & & \multicolumn{5}{c}{ Parameters } \\
\cline { 3 - 7 } Sex & $\mathrm{M}$ & 0.77 & $0.46-1.28$ & 0.67 & $0.31-1.44$ & $>0.05$ \\
& $\mathrm{~F}$ & 1.14 & $0.89-1.46$ & 1.49 & $0.70-3.18$ & $>0.05$ \\
\hline DM 2 & & 3.75 & $1.33-10.56$ & 4.68 & $1.46-14.97$ & 0.005 \\
\hline Smoking & & 2.43 & $0.98-6.41$ & 2.81 & $0.99-8.44$ & 0.049 \\
\hline Burdened heredity & & 0.98 & $0.79-1.22$ & 0.93 & $0.42-2.05$ & $>0.05$ \\
\hline \multirow{2}{*}{ BMI, kg/m ${ }^{2}$} & 224.9 & 0.28 & $0.12-0.65$ & 0.21 & $0.08-0.56$ & 0.001 \\
& $25-29.9$ & 0.98 & $0.62-1.56$ & 0.97 & $0.46-2.02$ & $>0.05$ \\
& $\geq 30.0$ & 1.87 & $1.18-2.97$ & 2.90 & $1.37-6.13$ & 0.004 \\
\multirow{2}{*}{ AGT gene genotypes } & TT & 0.87 & $0.37-2.04$ & 0.85 & $0.31-2.32$ & $>0.05$ \\
& TC & 1.11 & $0.82-1.52$ & 1.26 & $0.61-2.62$ & $>0.05$ \\
& CC & 0.88 & $0.50-1.56$ & 0.84 & $0.38-1.86$ & $>0.05$ \\
\hline \multirow{2}{*}{ AGT gene alleles } & T-allele & 1.02 & $0.76-1.36$ & 1.03 & $0.62-1.73$ & $>0.05$ \\
& C-allele & 0.99 & $0.79-1.23$ & 0.97 & $0.58-1.62$ & $>0.05$ \\
\hline Angiotensin II blood increase & & 4.38 & $2.50-7.67$ & 28.0 & $10.47-74.89$ & $<0.001$ \\
\hline
\end{tabular}

$\mathrm{M}$ - males, F - females, DM2 - diabetes mellitus type 2, BMI - body mass index, AGT - angiotensinogen, $\mathrm{RR}$ - risk ratio, $\mathrm{OR}$ - odds ratio, $95 \% \mathrm{CI}$ - confidence intervals

\section{Results}

The distribution of genotypes and alleles of AGT T704C gene polymorphism in EAH patients did not significantly differ from that in the control group (Tab. 1). Patients with TT genotypes were by $30 \%$ more likely to have burdened heredity as compared with the control group subjects of the same genotype ( $80 \%$ vs $50 \%$ respectively); patients with CC-genotype had DM2 almost twice as often as compared to patients with TT-genotype (37\% vs $20 \%$, respectively); there were three times more TC-genotype patients who smoked as compared to the control group (23\% vs $7.4 \%$ ). The body mass index (BMI) in the TC-genotype patients of both genders, males and females, was higher than in the control group by $22.22 \%(p=0.012)$ and $26.74 \%(p=0.01)$, respectively.
Moreover, female patients who were TC-genotype carriers had a significantly higher BMI than TT- and CC-genotype female patients, namely by $19.11 \%$ and $15.04 \%(\mathrm{p}<0.05)$.

The number of the TC-genotype patients with obesity of degree in range of (1-3) prevailed in the control group of TC-subjects by 3.8 times (28\% vs $7.4 \%$ ) and 5.4 times ( $40 \%$ vs $7.4 \%$ ), respectively.

Depending of genotype, WHR in males did not differ either in the control group or in EAH patients. However, the elevated WHR was more frequently observed in hypertensive women regardless of the AGT gene genotypes as compared to the female control group: $88 \%$ vs $0 \%$ for TT-genotype, $87 \%$ vs $23.5 \%$ for TC-genotype and $69 \%$ vs $40 \%$ for CC-genotype. 
Tab. 3. AGT gene alleles and genotypes as predictors of type 2 diabetes mellitus. obesity and blood pressure elevation.

\begin{tabular}{|c|c|c|c|c|c|c|}
\hline \multirow{2}{*}{ Potential risk factor } & & \multicolumn{5}{|c|}{ Parameters } \\
\hline & & $\mathrm{RR}$ & $95 \%$ CI RR & OR & 95\% CI RR & $\mathrm{p}$ \\
\hline \multicolumn{7}{|l|}{ DM 2} \\
\hline \multirow{3}{*}{ AGT gene genotypes } & TT & 0.69 & $0.19-2.53$ & 0.61 & $0.12-3.16$ & $>0.05$ \\
\hline & $\mathrm{TC}$ & 0.82 & $0.39-1.74$ & 0.76 & $0.27-2.17$ & $>0.05$ \\
\hline & $\mathrm{CC}$ & 1.50 & $0.71-3.19$ & 1.79 & $0.58-5.52$ & $>0.05$ \\
\hline \multirow{2}{*}{ AGT gene alleles } & T-allele & 0.77 & $0.44-1.33$ & 0.70 & $0.33-1.48$ & $>0.05$ \\
\hline & C-allele & 1.29 & $0.75-2.24$ & 1.43 & $0.68-3.02$ & $>0.05$ \\
\hline \multicolumn{7}{|l|}{ Obesity } \\
\hline \multirow{3}{*}{ AGT gene genotypes } & $\mathrm{TT}$ & 1.17 & $0.90-1.53$ & 1.49 & $0.76-2.94$ & $>0.05$ \\
\hline & $\mathrm{TC}$ & 1.63 & $1.01-2.64$ & 2.93 & $1.11-7.79$ & 0.03 \\
\hline & $\mathrm{CC}$ & 0.68 & $0.38-1.19$ & 0.44 & $0.15-1.28$ & $>0.05$ \\
\hline \multirow{2}{*}{ AGT gene alleles } & T-allele & 1.06 & $0.80-1.41$ & 1.14 & $0.58-2.22$ & $>0.05$ \\
\hline & C-allele & 0.95 & $0.71-1.26$ & 0.88 & $0.45-1.71$ & $>0.05$ \\
\hline \multicolumn{7}{|l|}{ BP elevation grade $2-3$} \\
\hline \multirow{3}{*}{ AGT gene genotypes } & TT & 2.07 & $1.33-3.21$ & 6.33 & $1.24-32.38$ & 0.018 \\
\hline & $\mathrm{TC}$ & 1.72 & $0.99-3.20$ & 2.56 & $1.01-6.87$ & 0.0499 \\
\hline & $\mathrm{CC}$ & 0.09 & $0.01-0.61$ & 0.04 & $0.01-0.32$ & $<0.001$ \\
\hline \multirow{2}{*}{ AGT gene alleles } & T-allele & 2.01 & $1.37-2.93$ & 3.64 & $1.82-7.28$ & $<0.001$ \\
\hline & C-allele & 0.50 & $0.34-0.73$ & 0.27 & $0.14-0.55$ & $<0.001$ \\
\hline
\end{tabular}

DM2 - diabetes mellitus 2 type, AGT - angiotensinogen, RR - risk ratio, OR - odds ratio,. 95\%CI - confidence intervals

Tab. 4. Blood pressure levels depending on AGT T704C polymorphism.

\begin{tabular}{|c|c|c|c|}
\hline Group & Genotype & Systolic blood pressure. $\mathrm{mmHg}$ & Diastolic blood pressure. $\mathrm{mmHg}$ \\
\hline \multirow{3}{*}{ Control group } & $\mathrm{TT}, \mathrm{n}=8$ & $117.52 \pm 3.0$ & $77.51 \pm 3.0$ \\
\hline & $\mathrm{TC}, \mathrm{n}=27$ & $116.92 \pm 4.0$ & $76.23 \pm 4.9$ \\
\hline & $\mathrm{CC}, \mathrm{n}=15$ & $115.74 \pm 4.3$ & $75.72 \pm 4.3$ \\
\hline \multirow[t]{3}{*}{ Study group } & $\mathrm{TT}, \mathrm{n}=10$ & $160.0 \pm 9.09 \mathrm{p}<0.001$ & $99.0 \pm 5.64 \mathrm{p}<0.001$ \\
\hline & $\mathrm{TC}, \mathrm{n}=49$ & $151.98 \pm 12.29 p<0.001$ & $94.30 \pm 6.09 p<0.001$ \\
\hline & $\mathrm{CC}, \mathrm{n}=19$ & $150.0 \pm 10.0 p<0.001 ; p=0.056$ & $91.58 \pm 6.24 p<0.001 ; p_{<}<0.05$ \\
\hline
\end{tabular}

$\mathrm{p}$ - significance of differences with control group of the same genotype, $\mathrm{p}_{\mathrm{TT}} \cdot \mathrm{p}_{\mathrm{TC}}$ - significance of differences for TT-. TC-genotypes carriers in particular group (control/patients)

Common EAH predictors in observed population are presented in Table 2 .

The SBP and DBP values in the control group depending on AGT $(704 T>C)$ gene polymorphism did not differ (Tabs 3, 4). There was also no significant difference between the $\mathrm{BP}$ values in patients with $T C$ - and $C C$-genotypes ( $p>0.05$ ). Instead, the $C$ allele carriers (especially the $C C$-genotype patients) had lower rates of SBP and DBP than TT-genotype patients, namely by $6.25 \%$ $(\mathrm{p}=0.056)$ and $7.49 \%(\mathrm{p}<0,05)$, respectively.

One-way ANOVA analysis did not confirm the association of AGT $(704 T>C)$ gene polymorphism with SBP and DBP values in the control group ( $\mathrm{F}=0.68 ; \mathrm{p}>0.05)$, but the $A G T$ gene is associated with SBP and DBP elevation in EAH patients $(\mathrm{F}=7.80$; $\mathrm{p}<0.001$ and $\mathrm{F}=4.90 ; \mathrm{p}=0.01$, respectively), as well as with BMI, albeit only in women $(\mathrm{F}=13.94 ; \mathrm{p}<0.001)$.

\section{Discussion}

The associations of BMI and BP, DM 2 in EAH patients were studied in plenty of researches. The Framingham Study demonstrated that both men and women had an increase in blood pressure with overweight (13). Noce A. et al. found a positive relationship of overweight or obesity with hypertension (20). In our former studies, we have proved the association of BMI increase with BP elevation and some genetic polymorphisms $(14,21)$.

Our results confirm the data of some studies where BMI and obesity correlates positively with $\mathrm{BP}(13,16,20)$. Leggio $\mathrm{M}$. et al. updated a comprehensive overview on vicious twins and found a relationship between obesity and hypertension, namely that about $75 \%$ of cases of hypertension were directly correlated to the contextual presence of obesity characterized as a form of hypertension referred to as obesity-related hypertension (16). These findings correspond to our results, in particular, almost $1 / 3$ of patients with EAH with grades 2-3 (31.3 $\%$ ) in our study have concomitant DM2, while only every one-fifth of patients with EAH grade 1 suffered from DM2 (19.4\%).

Several recent studies proved that the urinary AGT excretion level was associated strongly with elevated BP in normotensive people, thus suggesting the feasibility of using this parameter as a biomarker for hypertension (22, 23). Dahabiyeh et al (2020) has recently conducted a pilot study and gave evidence for the conversion of reduced form of AGT to its oxidized form to be directly linked to inadequate antioxidant status, which may contribute to the hypertension in pre-eclamptic pregnancy (24). Zitouni et al evaluated the contribution of angiotensinogen M235T and T174M gene variants and haplotypes to preeclampsia and its severity in (North African) Tunisians (25).

We have found no direct association of the AGT T704C polymorphism with obesity and DM2. However, T-allele (TT- and TCgenotypes) became a strong predictor of severe EAH course (BP elevation up to grade 2-3). Our results were partially confirmed by the data of Deborah de Farias et al. where AGT genotypes evidenced no significant differences regardless of sex or BMI categories including overweight/obesity (26). To sum up, the RAAS system might not be involved in overweight, obesity and DM2, at least based on AGT T704C gene's polymorphism. However, further studies might be needed to elucidate this question.

\section{Conclusion}

Smoking, DM2 and obesity increase the risk of EAH in the examined population 2.5 fold $(\mathrm{OR}=2.81 ; \mathrm{p}=0.049), 3.75$ fold $(\mathrm{OR}=4.68 ; \mathrm{p}=0.005)$ and twofold $(\mathrm{OR}=2.90 ; \mathrm{p}=0.004)$, respectively. The probability of EAH quadruplicates with elevation of serum angiotensin II. Genotypes and alleles of the AGT $(704 T>C)$ 
gene are not risk factors for DM2 and obesity in the examined population. $T$-allele of the $A G T$ gene $(704 T>C)$ increases the risk of BP elevation up to rade 2-3 (OR $=3.64 ; \mathrm{p}<0.001)$, whereas the $\mathrm{C}$-allele of the AGT $(704 \mathrm{~T}>\mathrm{C})$ gene is protective (especially the $\mathrm{CC}$-genotype) and reduces the relative risk almost by half for high rates of $\mathrm{BP}$ elevation in patients with $\mathrm{EAH}(\mathrm{OR}=0.27$; $\mathrm{p}<$ $0.001)$. One-way ANOVA analysis confirmed the association of AGT $(704 T>C)$ gene polymorphism with SBP and DBP elevation in $\mathrm{EAH}$ patients $(\mathrm{F}=7.80 ; \mathrm{p}<0.001$ and $\mathrm{F}=4.90 ; \mathrm{p}=0.01$, respectively), especially in TT-genotype carriers $(\mathrm{p}<0.05)$ and with BMI increase, albeit only in women $(F=13.94$; $p<0.001)$.

\section{References}

1. NCD Risk Factor Collaboration. Worldwide trends in blood pressure from 1975 to 2015: a pooled analysis of 1479 populationbased measurement studies with 19.1 million participants. Lancet 2017; 389: 37-55. DOI: 10.1016/S0140-6736(16)31919-5.

2. Bryan W, Mancia G, Spiering W et al. 2018 ESC/ESH Guidelines for the management of arterial hypertension. The Task Force for the management of arterial hypertension of the European Society of Cardiology (ESC) and the European Society of Hypertension (ESH). Eur Heart J 2018; 39: 3021-3104, https://doi.org/10.1093/eurheartj/ehy339.

3. Ji LD, Li JY, Yao BB, Cai XB, Shen QJ, Xu J. Are genetic polymorphisms in the renin-angiotensin-aldosterone system associated with essential hypertension? Evidence from genome-wide association studies. J Hum Hypertens 2017; 31: 695-698. https://doi.org/10.1038/jhh.201729.

4. Saidov MZ, Mammaev SN, Magadova HM et al. Genetic polymorphism of renin-angiotensin-aldosterone system in type 2 diabetes and in combination with arterial hypertension among Dagestan inhabitants. Diabetes Mellitus 2020; 22(6): 568-576. https://doi.org/10.14341/DM10207.

5. Benjamin EJ, Muntner P, Alonso A et al. Heart disease and stroke statistics - 2019 update: a report from the American Heart Association. Circulation 2019; 139(10): e1-e473. DOI: 10.1161/CIR.0000000000000659.

6. Pimphen Charoen, Jakris Eu-ahsunthornwattana, Nisakron Thongmung et al. Contribution of Four Polymorphisms in Renin-Angiotensin-Aldosterone-Related Genes to Hypertension in a Thai Population. Int J Hypertens 2019; 2019: Article ID 4861081. https://doi.org/10.1155/2019/4861081.

7. Xu Y, Rong J, Zhang Z. The emerging role of angiotensinogen in cardiovascular diseases. J cell physiol 2020 (cited 2020 November 30). Available from: URL: https://doi.org/10.1002/jcp.29889.

8. Sheremet MI, Sydorchuk LP, Shidlovskyi VO et al. The activity of proliferation and apoptosis of thyrocytes in the thyroid tissue of patients of nodular goiter with autoimmune thyroiditis considering the polymorphism of the BCL-2 (RS17759659), CTLA-4 (RS231775), APO-1/FAS (RS2234767) genes. Biointerface Res Appl Chem 2020; 10 (2): 5201-5208. https://doi. org/10.33263/BRIAC102.201208.

9. Paz Ocaranza M, Riquelme JA, García L et al. Counter-regulatory renin-angiotensin system in cardiovascular disease. Nat Rev Cardiol 2020; 17: 116-129. https://doi.org/10.1038/s41569-019-0244-8 .

10. Kooffreha ME, Anumudu CI, Akpan EE, Ikpeme EV, Kumar PL. A study of the M235T variant of the angiotensinogen gene and hypertension in a sample population of Calabar and Uyo, Nigeria. Egypt J Med Hum 2013; 14: 13-19.

11. Sydorchuk LP, Ursuliak YV. Genes allele status of angiotensinconverting enzyme (I/D) and endothelial nitric oxide synthase ( $894 \mathrm{G}>\mathrm{T})$ in patients with acute coronary syndrome. Lik Sprava 2015; 5-6: 24-34.

12. Balewgizie $S$ Tegegne, Tengfei Man et al. Heritability and the Genetic Correlation of Heart Rate Variability and Blood Pressure in $>29000$ Families.
Hypertension 2020; 76 (4): 1256-1262. https://doi.org/10.1161/HYPERTEN SIONAHA.120.15227Hypertension

13. Aronow WS. Association of obesity with hypertension. Ann Transl Med 2017; 5(17): 350. https://doi.org/10.21037/atm.2017.06.69.

14. Sydorchuk LP, Sokolenko AA, Sydorchuk AR et al. Insulin resistance in patients with arterial hypertension and abdominal obesity depending on ace and ppar- $\gamma 2$ genes polymorphism: A new opinion concerning an old problem. New Armen Med J 2015; 9 (2): 43-51.

15. Smyth LJ, Cañadas-Garre M, Cappa RC, Maxwell AP, McKnight AJ. Genetic associations between genes in the renin-angiotensin-aldosterone system and renal disease: a systematic review and meta-analysis. BMJ Open 2019; 9 (4): e026777. https://doi.org/10.1136/bmjopen-2018-026777.

16. Leggio M, Lombardi M, Caldarone E, Severi P, D’Emidio S, Armeni M. The relationship between obesity and hypertension: An updated comprehensive overview on vicious twins. Hypertens Res 2017; 40: 947-963. DOI: 10.1038/hr.2017.75.

17. Sydorchuk L, Dzhuryak V, Sydorchuk A et al. The cytochrome 11B2 aldosterone synthase gene rs 1799998 single nucleotide polymorphism determines elevated aldosterone, higher blood pressure, and reduced glomerular filtration, especially in diabetic female patients. Endocr Regul 2020; 54 (3): 217-226. DOI:10.2478/enr-2020-0024.

18. Dzhuryak VS, Sydorchuk LP, Sydorchuk AR et al. The cytochrome 11B2 aldosterone synthase gene CYP11B2 (RS1799998) polymorphism associates with chronic kidney disease in hypertensive patients. Biointerface Res Appl Chem 2020; 10: 5406-5411. https://doi.org/10.33263/BRIAC103.406411

19. Sydorchuk LP, Dzhuryak VS, Sydorchuk AR et al. Association of lipids' metabolism disorders with aldosterone synthase CYP11B2 (-344C/T) gene polymorphism in hypertensive patients depending on glomerular filtration rate. PharmacologyOnLine 2020; 2: 230-242.

20. Noce A, Daniele ND. The "Weight" of Obesity on Arterial Hypertension, Understanding the Molecular Crosstalk in Biological Processes. IntechOpen 2019. DOI: $10.5772 /$ intechopen. 87774.

21. Sydorchuk LP, Serdulets YI, Sydorchuk AR et al. The polymorphism of matrilin-3 (rs77245812) and interleukin-10 (rs 1800872) genes in osteoarthritis patients with arterial hypertension, obesity and type 2 diabetes mellitus. Arch Balk Med Union 2017; 52 (4): 422-429.

22. Sato E, Wang AY, Satoh M et al. Urinary angiotensinogen excretion level is associated with elevated blood pressure in the normotensive general population. Am J Hypertens 2018; 31: 742-749. https://doi.org/10.1093/ajh/hpy020.

23. Zou J, Li Y, Li FH, Wei FF, Wang JG. Urinary angiotensinogen excretion and ambulatory blood pressure. J Hypertens 2012; 30: 2000-2006. DOI: 10.1097/HJH.0b013e3283576928.

24. Dahabiyeh LA, Tooth D, Kurlak LO, Mistry HD, Pipkin FB, Barrett DA. A pilot study of alterations in oxidized angiotensinogen and antioxidants in pre-eclamptic pregnancy. Sci Rep 2020; 10: 1956. https://doi.org/10.1038/ s41598-020-58930-7.

25. Zitouni H, Gannoum M, Raguema N et al. Contribution of angiotensinogen $\mathrm{M} 235 \mathrm{~T}$ and $\mathrm{T} 174 \mathrm{M}$ gene variants and haplotypes to preeclampsia and its severity in (North African) Tunisians. J Renin Angiotensin Aldosterone Syst 2018; 1. https://doi.org/10.1177\%2F1470320317753924.

26. Deborah de Farias, Alexandre Costa Pereira, José Eduardo Krieger, José Geraldo Mill, Sérgio Henrique Sousa Santos, Marcelo Perim Baldo. Polymorphisms of the renin-angiotensin system are not associated with overweight and obesity in a general adult population. Arch Endocrinol Metab [online] 2019; 63 (4): 402-410. http://dx.doi.org/10.20945/23593997000000155 .

Received December 18, 2020. Accepted March 24, 2021. 